Thorax (1955), 10, 99.

\title{
CONGENITAL TUBERCULOSIS \\ REPORT OF A CASE WITH NECROPSY FINDINGS IN MOTHER AND CHILD
}

\author{
BY \\ BERYL D. CORNER AND N. J. BROWN \\ From the United Bristol Hospitals and Southmead Hospital, Bristol
}

(RECEIVED FOR PUBLICATION FEBRUARY 18, 1955)

The birth into the world of an infant already infected in utero with tuberculosis is an event of such rarity that the presentation of one further case, which appears to be only the thirteenth recorded in the British Isles, would seem to be justified, especially as the unusual opportunity was afforded of studying the pathological changes at necropsy in both mother and baby.

There are three possible routes by which tubercle bacilli may pass from an infected mother to her unborn child. (1) The blood stream of the foetus may be infected from an infected placenta by the passage of organisms through the umbilical vein. In such a case a primary tuberculous complex is usually established in the liver and the lymph nodes of the porta hepatis. It is, however, possible for the organisms to by-pass the liver by way of the ductus venosus and be carried through the right side of the heart to the lung, the primary complex then involving lung and hilar lymph nodes. (2) Infected amniotic fluid may be ingested by the foetus, in which case the primary complex might be expected to involve the intestine and mesenteric lymph nodes. (3) The foetus may aspirate infected amniotic fluid into its lungs resulting in widespread pulmonary infection. This appears to have been the mode of infection in our present case.

In assessing previous recorded cases it is necessary to establish certain criteria which must be fulfilled before a certain diagnosis of congenital tuberculosis can be made. The criteria which have been accepted by most authors are those laid down by Beitzke (1935). He maintained that to prove that the tuberculosis is truly congenital the tuberculous nature of the lesions in the infant must be proved. The tuberculous lesions must be present at or within a few days of birth, or a primary tuberculous complex must be found in the liver, or extrauterine infection must be excluded with certainty, the child being immediately separated from the mother and all other sources of tuberculous infection.

The literature was reviewed by Beitzke in 1935 when 61 cases of congenital tuberculosis and 40 cases of tuberculous bacillaemia (i.e., cases in which the infant died before there was time for lesions to develop) were accepted. Using the same criteria Hughesdon (1946) accepted a further six cases of congenital tuberculosis and one case of tuberculous bacillaemia from the literature and added her own four cases of congenital tuberculosis. We have been able to find 21 more cases published since that time or not included by the above authors which fulfil Beitzke's criteria (Buchanan, 1946; Pagel and Hall, 1946, 1948; Danjou, 1947; Daamen, 1947; Debré, Furiet-Laforet, and Royer, 1948; Wallgren, 1948; Jordan and Spencer, 1949; Lesné, Cayla, Roche, and Allard, 1949; Aufdermaur, 1947; Martrou and Martrou, 1950; Ballabriga Aguado, 1950; de la Barra and Donoso, 1949; Burgess, 1950; Germain, André, and Marty, 1950; Hertzog, Chapman, and Herring, 1949; Smeenk, 1950; Amick, Alden, and Sweet, 1950; Robertson and Sullivan, 1950; Horley, 1952). Other cases of probable congenital tuberculosis which do not seem to us to comply fully with the requirements laid down above have been reported by Dekker-Jonker (1946), Harris, McCullough, Stone, and Brock (1948), Amick, Alden, and Sweet (1950, Case 4), Leroux and Guillet (1950), Wagner (1952), and Harris and Trenchard (1952, Cases 2 and 3).

This brings the total number of proved cases of congenital tuberculosis of all types hitherto described in the world's literature to 133 . Of these the 12 which have occurred in the British Isles are those of Andrewes (1903), Morley (1929), Price (1937), Davin-Power (1941), Hughesdon (1946), Buchanan (1946), Pagel and Hall (1946, 1948), Jordan and Spencer (1949), and Horley (1952); this last case was also reported by Mason (1954).

\section{CASE REPORT}

INFANT'S HISTORY.-Rosemary F. was born on September 24, 1947, a vertex presentation delivered by forceps. At birth she weighed $5 \mathrm{lb} .15 \mathrm{oz}$., her appearance was normal, and she required minimal resuscitation. In view of the mother's condition the child was 
removed from the labour room directly after birth. Subsequently there was no further contact with the mother.

She was fed on a proprietary brand of modified dried milk and gained weight satisfactorily. On the 19th day, when it was noticed that her respirations had become rapid and panting, she was placed in an oxygen tent and a few hours later her temperature was found to be $104^{\circ} \mathrm{F}$. On the 20th day she was transferred to the Bristol Royal Hospital for Sick Children.

On admission to hospital on October 13 the baby weighed $6 \mathrm{lb} .3 \mathrm{oz}$, and appeared to be in a satisfactory state of nutrition. There was no cyanosis or pallor. Her rectal temperature was $100^{\circ} \mathrm{F}$., pulse 140 , and respiration rate still abnormally rapid at 60 per minute, but the child did not give the impression of severe illness and was not dyspnoeic. The only other abnormal finding was a few scattered rhonchi in both lungs.

At this stage the diagnosis of the mother's condition was still unknown, and, as it was assumed that the baby was developing acute bronchiolitis, treatment with penicillin by intramuscular injection and by atomizer into the oxygen tent was begun.

For three days feeds were taken well and the temperature fell to $98^{\circ} \mathrm{F}$., but the respiration rate still remained rapid and rose to 80 per minute. On October 17 the baby became reluctant to feed and the temperature rose to $100.6^{\circ} \mathrm{F}$., On the next day cyanosis developed during a bottle feed, and at 6 p.m. the child was pale, cold, and almost pulseless, and, despite attempts at resuscitation, she remained in a moribund condition and died at 7.45 a.m. on October 19, aged 25 days.

MOTHER's History.-E.F. at the age of 21 years was training as a student nurse when she developed a pain in the upper part of the back for which she did not seek medical advice. Six months later this pain became acute after a fall and in July, 1936, it was found that she had advanced caries of the fifth and sixth dorsal vertebrae. Shortly after this an Albee bone graft, fixing the upper eight dorsal vertebrae, was performed by Mr. Hey Groves.

Following a period of rest, she attempted to resume light nursing duties in 1937, but pain recurred and radiographs then showed a shadow suggestive of a paravertebral abscess at the site of the original lesion and some infiltration at both lung apices. she rested again for several months, but in February, 1938, there was an extension of the lesion to the ninth and tenth dorsal vertebrae and the paravertebral abscess was now much larger, its shadow extending the whole length of the dorsal spine radiologically. The lung lesions were apparently healing. For the next two years she was immobilized in a plaster bed in a sanatorium and was discharged home in April, 1941, wearing a brace and free from symptoms. Radiographs then showed fusion and rarefaction of the bodies of the upper eight dorsal vertebrae, collapse of the ninth and tenth, and some rarefaction of the eleventh. The erythrocyte sedimentation rate was $34 \mathrm{~mm}$. in the f.rst hour.

She remained under the regular supervision of the local tuberculosis dispensary staff and started part-time clerical work in 1942, gradually increasing to full-time $\overrightarrow{\overline{\vec{N}}}$ work in 1944. She then married, moved into Bristol, and $\overline{0}$ was first seen at the Bristol Chest Clinic in May, 1946. She seemed very well, weighed $8 \mathrm{st}$. $5 \mathrm{lb}$., and her only $\overline{\bar{\omega}}$ complaint was of lassitude. Radiographs showed no $\vec{\oplus}$ evidence of tuberculous activity in the dorsal spine: there were calcifed deposits at the lung apices.

She became pregnant in January, 1947, at the age $\overrightarrow{0}$ of 32 years, and at the eighth week was examined by Professor Drew Smythe, who found a normal pregnancy $\vec{\omega}$ and advised a Caesarean section at full term to avoid the o. effort of labour. Her expected date of delivery was October 25. The tuberculosis officer examined her at the twentieth week of pregnancy and found her general con- $\overrightarrow{0}$ dition satisfactory (weight 8 st. 9 lb.) and her radio- ? graphs unchanged from the previous year. Routine 6 antenatal examinations were subsequently carried out 윽 and the pregnancy appeared to be proceeding normally.

The membranes ruptured prematurely on September $23 c$ and slight labour pains began. On admission to a nursing home she stated that for a few days she had had "shivering attacks." She was found to be in labour and having $\vec{\theta}$ rigors with a temperature of $102^{\circ} \mathrm{F}$. to $104^{\circ} \mathrm{F}$. The foetus $\mathrm{G}$ appeared small and there was some doubt about the foetal heart sounds, so that Caesarean section was not indicated. At full dilatation on September 24 an unrotated occipitoposterior presentation was diagnosed, so that manual

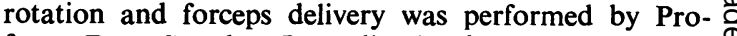
fessor Drew Smythe. Immediately after delivery a postpartum haemorrhage and obstetric shock occurred from which the mother recovered rapidly after manual removal of the placenta, which appeared normal.

During the next week the mother's condition remained grave with persistent pyrexia and rigors. There was no evidence of pelvic or urinary tract infection, blood culture was sterile, and blood count showed normocytic anaemia only. On the tenth day of the puerperium she was transferred to Ham Green Isolation Hospital for investigation.

On admission she was conscious and cheerful. Her temperature was $103^{\circ} \mathrm{F}$, pulse 138 , and respirations 28 per minute. Her complexion showed a hectic cyanotic $ᄋ$ flush and there were a few rales at both lung bases. The E.S.R. was $60 \mathrm{~mm}$. in the first hour and chest radiographs showed mottling in both lung fields. There was no sputum and only very slight occasional cough. Her $\sigma$ condition rapidly deteriorated with increasing cachexia, $N$ but no meningitic signs, and she died on October 16, 22 days after delivery.

A post-mortem examination was carried out by $\underset{<}{ }$ Dr. R. Aidin.

\section{Necropsy Findings IN THE ChILd}

Necropsy was carried out 27 hours after death. The body was that of a poorly nourished female infant showing no external abnormality. The umbilicus appeared healthy. The serous cavities were normal, as were the heart, aorta, and main blood vessels. The upper air passages contained a great deal of tenacious mucus. The lungs (Fig. 1) 


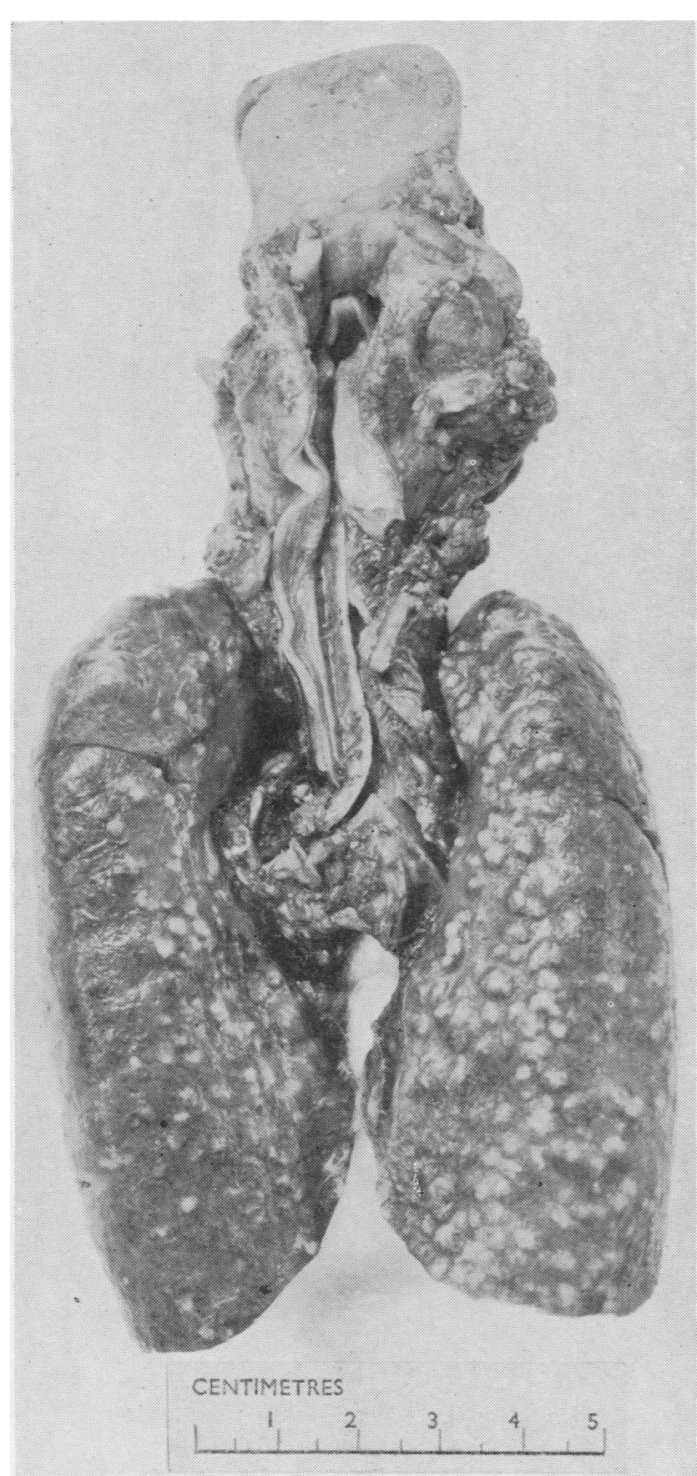

Fig. 1.-Posterior view of the infant's lungs.

felt almost completely solid and retained their shape after removal from the body. On section a vast number of caseous foci, each 2-3 $\mathrm{mm}$. in diameter, were found to be scattered throughout both lungs (Fig. 2). The lesions were all of approximately the same size, and no focus could be found which appeared older than the rest. The right lung was more severely affected than the left and the lesions were rather more numerous at the bases than at the apices. There were many tubercles immediately beneath the visceral pleura, but the pleural cavities were not involved. Several enlarged lymph nodes showing massive caseation were found at the hilum of each lung. A careful search of the rest of the body revealed no other tuberculous lesions and no abnormalities were found in the other organs.

Histologically the lungs (Fig. 3) showed numerous, large, ill-defined necrotizing and caseating lesions which were swarming with acid-fast bacilli. At the edges of the necrotic foci there was curiously little inflammatory reaction. A few epithelioid cells and lymphocytes were found in places, but there were no giant cells and no fibroblastic proliferation was seen. Many of the lesions were closely related to bronchioles, but others were spreading indiscriminately into the lung tissue. The intervening alveoli were collapsed.

Sections of hilar lymph nodes showed similar caseating lesions with enormous numbers of acidfast bacilli. Sections of the liver and spleen showed no tuberculous lesions, but in both organs acid-fast bacilli were seen lying within the blood vessels.

Culture of caseous material from the lungs on Loewenstein-Jensen medium yielded a pure growth of M. tuberculosis of human type.

\section{NeCROPSY Findings IN THE MOTHER}

There was extensive tuberculous caries of the dorsal spine with a large paravertebral abscess. The bone graft was still firmly in position.

Miliary tubercles were found scattered throughout both lungs and there were healed scars at both apices. No cavitation was present.

No tuberculous lesions were found in the other organs. The pelvic viscera appeared healthy.

\section{Discussion}

This case fulfils the criteria of Beitzke. The tuberculous nature of the lesions in the lungs and hilar lymph nodes of the infant have been proved both histologically and bacteriologically. The baby was immediately separated from the mother, so that extrauterine infection from her can be excluded. The father and the nurses who looked after the child had no evidence of tuberculous infection. The nature of the mother's febrile illness was unknown at the time of delivery, but in retrospect it is clear that she must then have been suffering from a blood-borne spread of tuberculosis from the chronic focus in the spine. During this process an infection of the amniotic fluid must have occurred, and by aspiration the infection was carried to the baby's lungs. The distribution of the lesions in the infant's lungs points to a massive infection by way of the air passages rather than by the blood stream.

It is unlikely that at the time of delivery the mother was capable of causing an air-borne infection, since 
Right Posterior-Anterior

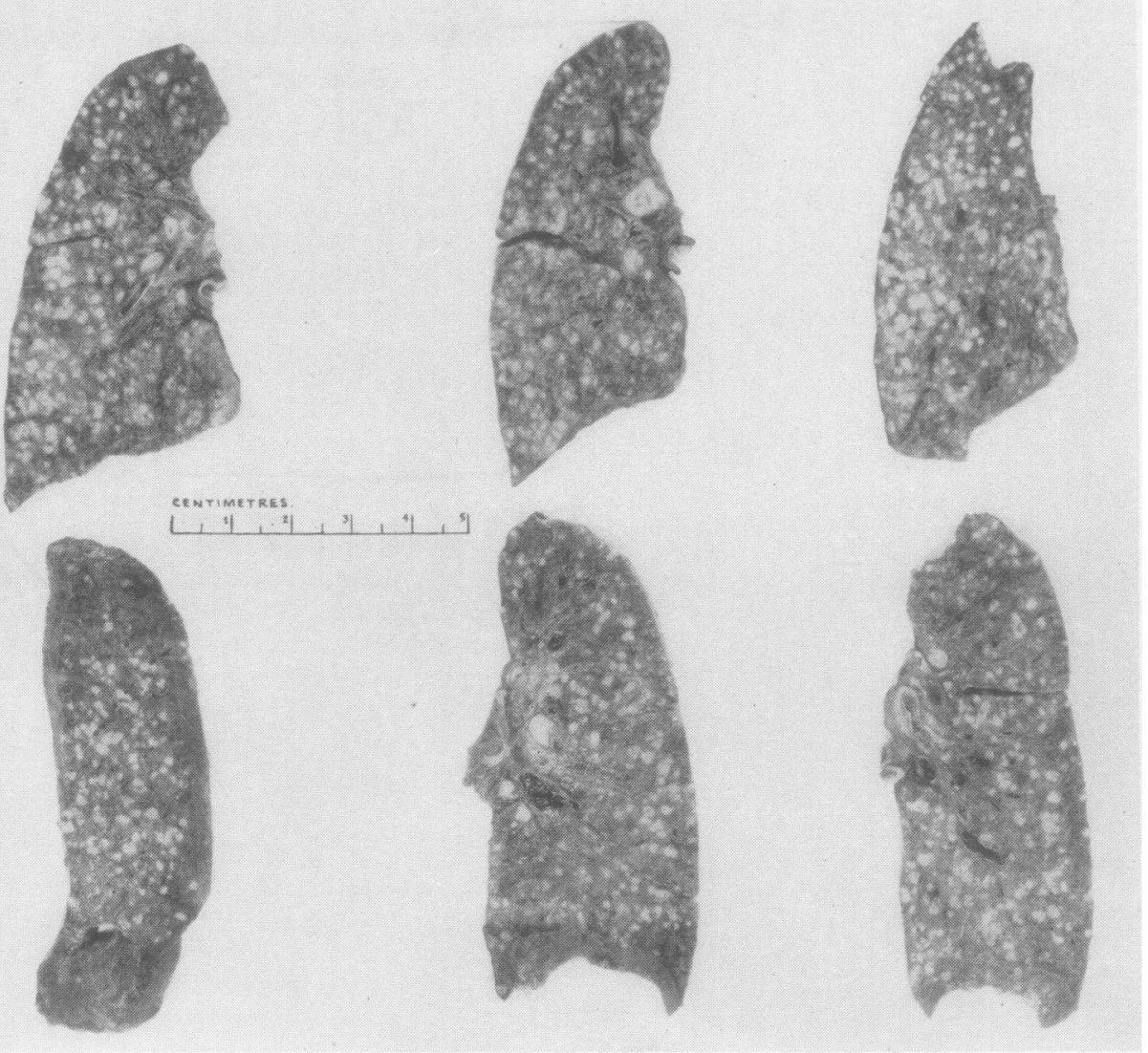

Left Anterior-Posterior

FIG. 2.-Gross appearance of slices of infant's lungs.

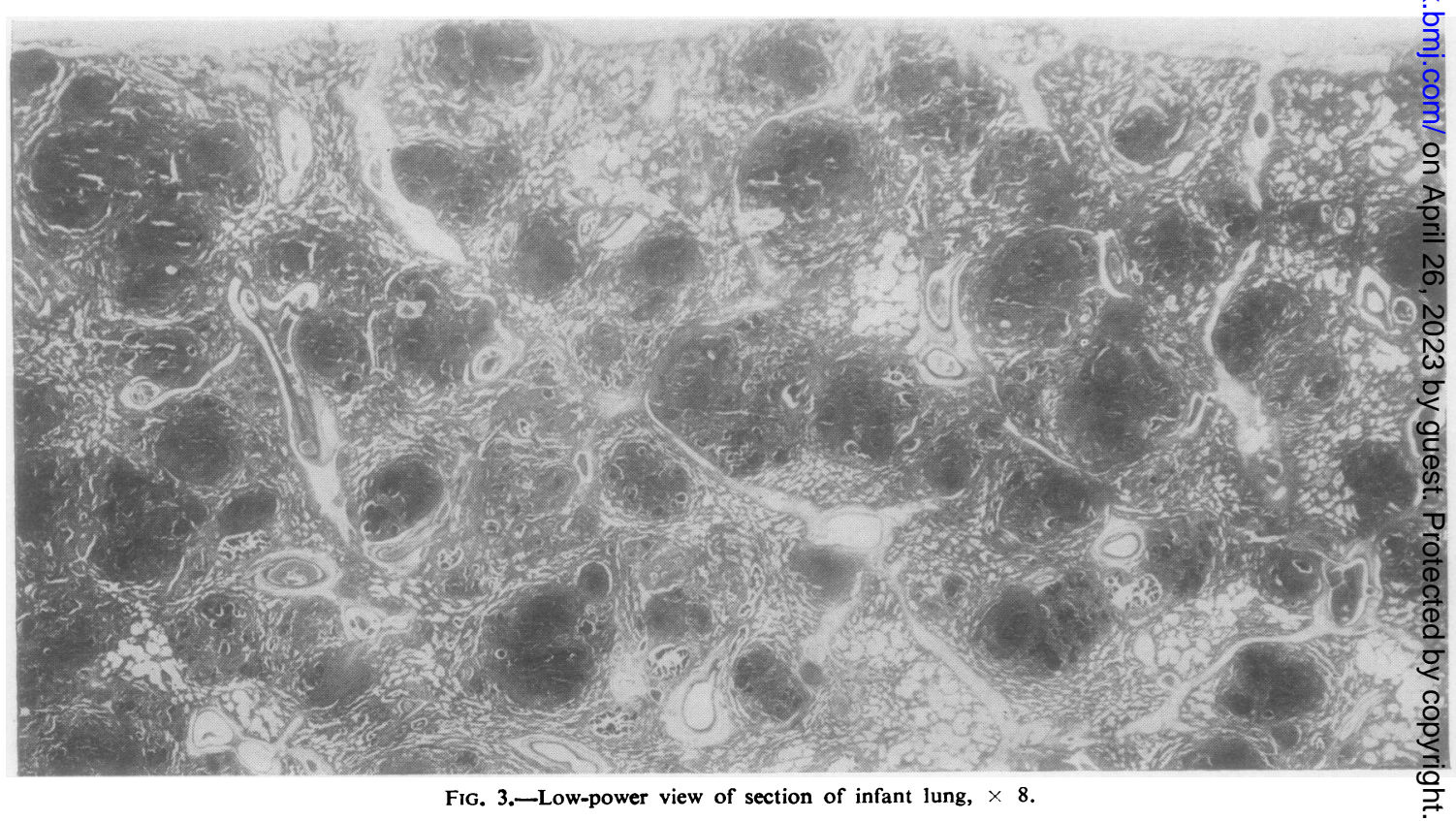


even at necropsy 22 days later the pulmonary infection was entirely a miliary one. There was no " open" lesion and at no time had she produced any sputum.

Congenital tuberculosis of this so-called " aspiration" type is less common than the blood-borne type in which a primary focus is found in the infant's liver. The pathological findings resemble those described by other authors, who have also noted the massive necrotic nature of the lesions without the characteristic cellular reaction usually found in tuberculosis.

Until the last few years congenital tuberculosis was regarded as a virtually untreatable condition (even if diagnosed during life) and appears to have been uniformly fatal. With the advent of streptomycin, however, a possible therapeutic agent has become available. Wallgren (1948) first recorded the use of this drug in the condition. In his case the mother suffered from pulmonary tuberculosis. The baby, who was immediately separated from the mother, survived with streptomycin treatment for 104 days and at necropsy was found to have tubercles in the lungs, spleen, and meninges, with a primary complex in the liver. Lesné and others (1949) reported a case in which the mother was suffering from tuberculous meningitis at the time of delivery. The baby, immediately isolated, also developed tuberculous meningitis from which, after streptomycin treatment, it recovered without sequelae. Further recoveries after streptomycin treatment of what appear to be certain cases of congenital tuberculosis have been described by Martrou and Martrou (1950) and Amick and others (1950), but in the latter case the child showed some mental retardation. Other recoveries are reported by Harris and Trenchard (1952), but since their two infants were not immediately separated from the mothers at birth they can only be regarded as possible cases.

\section{SUMMARY}

The literature on the subject of congenital tuberculosis has been reviewed and the cases reported in the last eight years assessed.
A case of congenital tuberculosis is described in which the infant died at the age of 25 days and was found at necropsy to have numerous necrotizing and caseating tuberculous lesions in the lungs and hilar lymph nodes. The mother suffered from a chronic tuberculous lesion of the spine and developed blood-borne miliary spread of the infection about the time of delivery. She died 22 days after delivery and the diagnosis was confirmed at necropsy. It is considered that the infant became infected by aspirating into the lungs amniotic fluid containing tubercle bacilli.

Our most grateful thanks are due to Professor H. J. Drew Smythe for the loan of notes and permission to publish the obstetric details, to Dr. A. T. M. Roberts for the loan of notes from Bristol Chest Clinic and Ham Green Hospital, to Professor T. F. Hewer for much helpfuladvice, to Dr. R. Aidin for the post-mortem report on the mother, to Mr. G. H. Rogers for the photographs, and to Dr. U. Mesdag for translations of Dutch articles.

\section{REFERENCES}

Amick, F. E., Alden, M. W., and Sweet, L. K. (1950). Pediatrics, 6, 384

Andrewes, F. W. (1903). Trans. path. Soc. Lond., 54, 142.

Aufdermaur, M. (1947). Schweiz. Z. Tuberk., 4, 199.

Ballabriga Aguado, A. (1950). Rev. esp. Pediat., 6, 31.

Barra, A. de la, and Donoso, S. (1949). Bol. Soc. chil. Obstet. Ginec., $14,137$.

Beitzke, H. (1935). Ergebn. ges. TuberkForsch., 7, 1.

Buchanan, J. (1946). Glasg. med. J., 27, 13

Burgess, J. R., jr. (1950). N. C. med. J., 11, 239

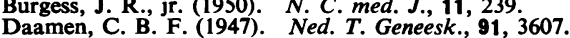

Daamen, C. B. F. (1947). Ned. T. Genees

Davin-Power, M. (1941). Brit. med. J., 1, 13

Debré, R., Furiet-Laforet (Mme.), and Royer, P. (1948). Arch. franc. Pédiat., $5,225$.

Dekker-Jonker, A. (1946). Maandschr. Kindergeneesk., 14, 26

Germain, A., André, L., and Marty, J. (1950). Bull. Soc. Méd. Hôp., Paris, 66, 629.

Harris, E. A., McCullough, G. C., Stone, J. J., and Brock, W. M. (1948). J. Pediat., 32, 311.

Harris, W. C., and Trenchard, H. J. (1952). Tubercle, Lond., 33, 273. Hertzog, A. J., Chapman, S., and Herriny, J. (1949). Amer. J. clin. Path., 19, 1139.

Horley, J.' F. (1952). Arch. Dis. Childh., 27, 167.

Hughesdon, M. R. (1946). Ibid., 21, 121.

Hughesdon, M. R. (1946). Ibid.,21, 121. Brit, med. J, 1, 217

Jordan, J. W., and Spencer, H. (1949). Brit. med. J., 1, 217.

Lesn', E., Cayla, A., Roche, G., and Allard (1949). Sem. Hôp. Paris, 25, 2803.

Martrou, N., and Martrou, P. (1950). Nourrisson, 38, 79.

Mason, N. (1954). Brit. med. J., 1,970.

Morley, R. H. (1929). Arch. dis. Childh., 4, 227.

Pagel, W., and Hall, S. (1946). Tubercle, Lond., 27, 153.

- (1948). Ibid., 29, 32.

Price, D. (1937). Brit. J. Tuberc., 31, 264

Robertson, H. E., and Sullivan, C. F. (1950). Canad. med. Ass. J., 63, 361 .

Smeenk, C. (1950). Ned. T. Geneesk., 94, 169.

Wagner, S. (1952). Dtsch. GesundhWes., 7, 969.

Wallgren, A. (1948). Rev. esp. Pediat., 4, 264. 